\title{
Albumin Excretion Rate
}

National Cancer Institute

\section{Source}

National Cancer Institute. Albumin Excretion Rate. NCI Thesaurus. Code C150814.

A determination of the amount of albumin being excreted in a biological specimen over a defined period of time. 